\section{TOOTH MORPHOLOGY ON YOUR PHONE}

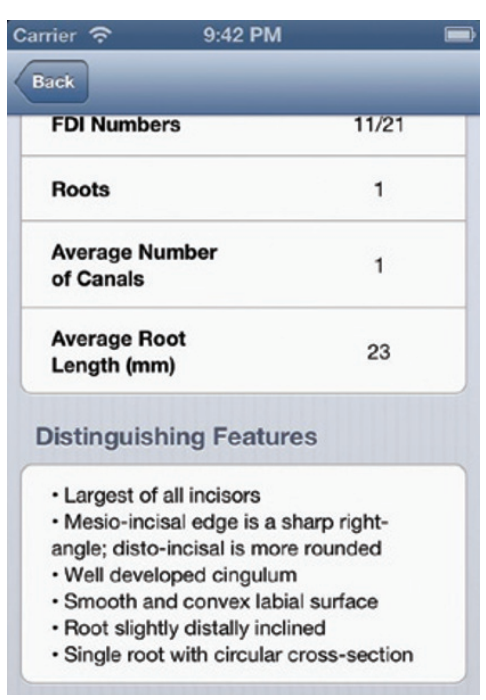

Sheffield dental student Prateek Biyani has released an app to 'bring tooth morphology to your fingertips'. The app is primarily targeted towards dental students in their early years of training, but is easy for anyone to use.

The app is a quick, brief and easy resource for basic and crucial information on tooth morphology and is quicker than reaching for a book. It features a touch-friendly interface and high quality images to demonstrate ideal morphology of the teeth. Three key areas are targeted: tooth development, morphology and distinguishing features. The design is clean and easy to navigate. Images can easily be accessed and upon swiping or tapping, they can be enlarged and viewed in greater detail by rotating your phone.

There is further information in a 'Definitions' page for beginners (currently iOS only).

Prateek told the $B D J$ : 'I love technology and decided I wanted to contribute some of my skills to the dental field. I didn't want something that had excessive amounts of information. Sometimes, particularly when you're a student, simple is best'.

The app is available at https:// itunes.apple.com/gb/app/toothmorphology/id699998293?ls=1 and https://play.google.com/store/ apps/details?id=com.prateekbiyani. morphology.

\title{
MAKING YOUR FINANCIAL LIFE EASIER
}

If value for money tops your list of priorities, then you need a tax solution that not only takes care of your returns but gives you the most in added benefits as well.

figurit is a specialist accountancy and tax solution created exclusively for dental associates, so your specific tax needs are fully understood.

figurit guarantees to file all of your returns within four weeks, and you also receive a good number of benefits for the fees that you pay.
The package offers a wide range of inclusive addons such as insurance to cover the costs of an HMRC inspection, interim tax estimates, user-friendly online bookkeeping software, and assistance with opening the best business bank account for your needs.

This accountancy and tax solution can also help you plan your financial future. figurit offers a free annual consultation with an expert advisor who can counsel you on pensions, investment opportunities and the like.

figurit can make your financial life not only easier, but also more profitable - now that's true value for your money.

For more information on figurit's specialist accountancy and tax package exclusively for dental associates, visit www.figurit.co.uk.

\section{OPTIMUM INSTRUMENT STERILISATION}

The Eurosonic 4D and 3D Ultrasonic Cleaners from Euronda provide even higher performance and are even easier to use.

For those who demand the very best, the Eurosonic $4 \mathrm{D}$ is the fully digital and electronic ultrasonic tank with four operating modules and a 3.5 litre capacity. The double operating range allows you to choose from six cycles with set times ranging between 10 and 40 minutes and temperatures ranging between 30 and $60{ }^{\circ} \mathrm{C}$. Its non-deformable semi-

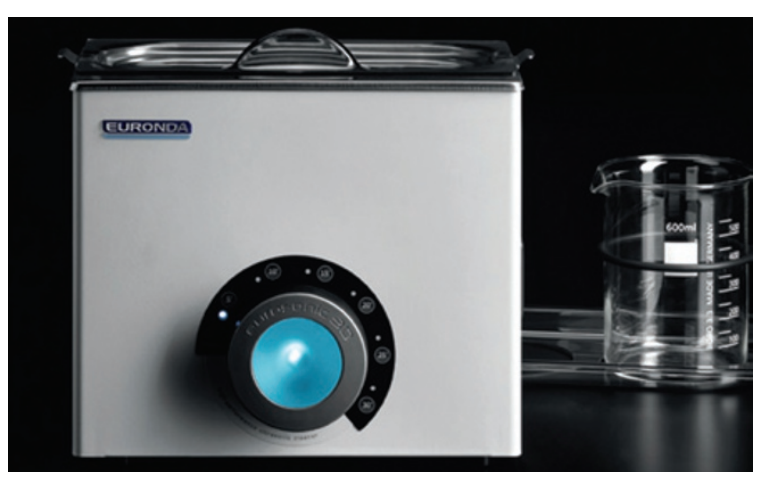

transparent cover also features a new anti-drip system.

The Eurosonic 3D presents a balanced choice. This electronic, digital ultrasonic tank features a piezoceramic transducer with double ceramic layer that makes the cleaning action particularly effective. It is also fitted with two side-handles for easier transport and a 3.0 litre stainless steel tank. The new backlit controller allows you to choose the duration of the treatment (0 to 30 minutes), with a constant $60{ }^{\circ} \mathrm{C}$ temperature.

You can be sure that both of these top-of-the-line ultrasonic tanks will deliver optimum instrument sterilisation.

Call The Dental Directory on 0800585586 or visit www.dentaldirectory.co.uk.

\section{A WHOLE NEW LEVEL OF PATIENT SECURITY}

The new eSignatures module from Carestream Dental is designed to ensure the quality of patient consent recorded. The system uses a DTU signature pad with biometric technology to authenticate the individual's signature. The biometrics record the pressure points, time taken and angle of the pen to ensure illegal duplication of the signature is almost impossible, offering a whole new level of security for your patients. Signatures can be provided in 'real-time'; patients can view the forms on the pad before signing the same document.

The module will streamline your workflow, as it can be used by any authorised member of the team. Fully integrated within the CS R4 Clinical+ practice management software, convenience is heightened, and forms can easily be retrieved or emailed to patients as required. www.carestreamdental.co.uk 